\title{
Analysis of a UWB Planar Antenna with Split Ring Resonator
}

\author{
Otávio Paulino Lavor, Carlos Gomes de Moura, Humberto César Chaves Fernandes and Marinaldo \\ Pinheiro de Sousa Neto
}

\begin{abstract}
In this work a new configuration of a ultrawideband (UWB) microstrip antenna is analyzed. A Split Ring Resonator (SRR) is inserted into a circular opening on the opposite side of the patch. The SRR structure will work as a band stop filter. Three configurations are discussed and one of these configurations has a bandwidth from 3.2 to $10.6 \mathrm{GHz}$ and notching a frequency band between 5.3 to $6.0 \mathrm{GHz}$. The prototype is built and results measured and simulated are compared.
\end{abstract}

Index Terms - Microstrip Antenna, SRR, UWB.

\section{INTRODUCTION}

The ultra-wideband communication system (UWB) occupies the frequency range 3.1 to $10.6 \mathrm{GHz}$, which is approved by the Federal Communications Commission [1]. UWB technology is a short-range wireless technology for transmitting large amounts of data and high speeds with very low power. To establish communication between two nodes, the UWB transceivers require antennas, preferably small in size and low production cost [2]. Several slit antennas for UWB application have been reported so far [3-5]. To avoid interference between UWB system and the system (WLAN), wireless local area network, a filter rejects-band on UWB system is needed. However, the use of a filter will increase the complexity of the UWB system. Therefore, a UWB antenna having reject-band for certain characteristic frequencies is an alternative to overcome this problem. Multiple antennas to reject-band have been reported [6-10].

In [10] the SRR is used in a truncated ground plane, obtaining a bandwidth of 3.6 to $9.2 \mathrm{GHz}$ with a reject band that covers the frequency of $5.5 \mathrm{GHz}$. This work propose a new micro strip antenna UWB with patch circular with rejects-

Otávio Paulino Lavor is with Campus Pau dos Ferros, Federal Rural University of the Semi-Arid, Pau dos Ferros, Brasil (e-mail: otavioplavor@gmail.com).

Carlos Gomes de Moura is with the Federal University of Rio Grande do Norte, Natal, Brasil (e-mail: carlosgomes@moura.in).

Humberto César Chaves Fernandes is with the Electrical Engineering Department, Federal University of Rio Grande do Norte, Natal, Brasil (e-mail: humbeccf@ct.ufrn.br ).

Marinaldo Pinheiro de Sousa Neto is with the Federal Institute of Education, Science and Technology of the Rio Grande do Norte, Mossoró, Brasil (e-mail: sousaneto1@gmail.com).

Digital Object Identifier 10.14209/jcis.2015.4 band designed for a resonant frequency of $5.8 \mathrm{GHz}$. The cutting band is achieved by inserting a conventional split ring resonator (SRR) in the circular opening made in the ground plane, which is magnetically excited by means of a circular patch on the opposite side of the dielectric substrate.

The SRR is composed of two strips of concentric rings with an opening. The two rings are positioned such that the opening of each ring is placed in front of the other. This opening tightly controls the resonant frequency. Basically, the SRR behaves as an LC resonator and the resonance frequency can be calculated as follows [11],

$$
\omega_{0}=\sqrt{\frac{2}{\pi r_{0} L_{0} C}},
$$

where $L_{0}$ is the inductance per unit length of the rings, $C$ is the total capacitance of the SRR, and $r_{0}$ is the mean radius of the two rings.

The SRR may be magnetically excited, if the rings are oriented correctly. To properly excite the SRR by a varying magnetic field, a significant component in the axial direction is required.

\section{DESIGN OF THE ANTENNA}

The geometry of the antenna pattern is a planar structure with a circular patch with a radius $r=6.0 \mathrm{~mm}$ which is connected to the supply line with a width $w=3.0 \mathrm{~mm}$ and a length $l=4.0 \mathrm{~mm}$. The antenna is built on an FR4 substrate 30 (a) $\mathrm{x} 30(\mathrm{~b}) \mathrm{mm}^{2}$ and thickness $1.56 \mathrm{~mm}$, dielectric constant $\varepsilon_{\mathrm{r}}$ $=4.4$ and loss tangent $\tan \delta=0.02$. A conductive plane is placed on one side of the substrate, which is the ground plane. For the proposed new antenna, it is considered the antenna parallel to the xy plane and centered at the origin of a Cartesian coordinate system (x, y, z). In this case, a circular opening centered on the origin of radius $R=11.0 \mathrm{~mm}$ is made in the ground plane. The system center is aligned along the $y$ axis. To implement the property of rejects band, the SRR is inserted into the circular opening in the ground plane underneath the patch radiating, as shown in Figure 1. Figure 1 also shows the standard antenna. This arrangement can achieve high magnetic coupling between the patch and the rings at resonance. The presence of the rings leads to a negative effective permeability within a narrow band above the resonance, where the signal propagation is inhibited. 


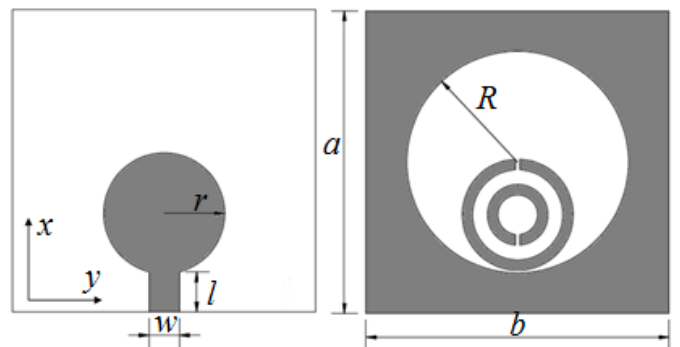

a)

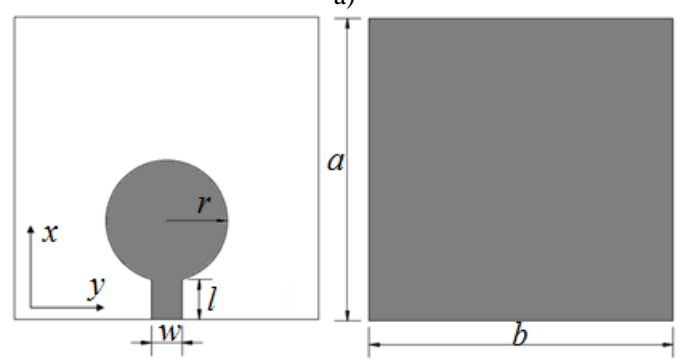

b)

FIG. 1. Geometry of the proposed(a) and standard(b) antenna.

Figure 2 shows the geometry of the proposed SRR. The SRR element for a resonant frequency of $5.5 \mathrm{GHz}$ dimensions are obtained as follows: $r_{1}=5.5 \mathrm{~mm}, r_{2}=3.0 \mathrm{~mm}, S=1.0$ $\mathrm{mm}, D=1.5 \mathrm{~mm}$ and $G=0.5 \mathrm{~mm} \mathrm{[10]}$.

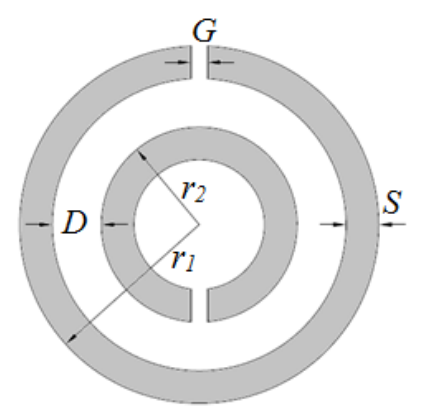

FIG. 2. Geometry of the proposed SRR.

To optimize the position of the SRR, three different configurations were tested (Figure 3): one below the patch $(10,15)$, a second positioned in the center of the ground plane $(15,15)$ and a third above the patch $(20,15)$. These antennas are called antenna 1,2 and 3 , respectively.
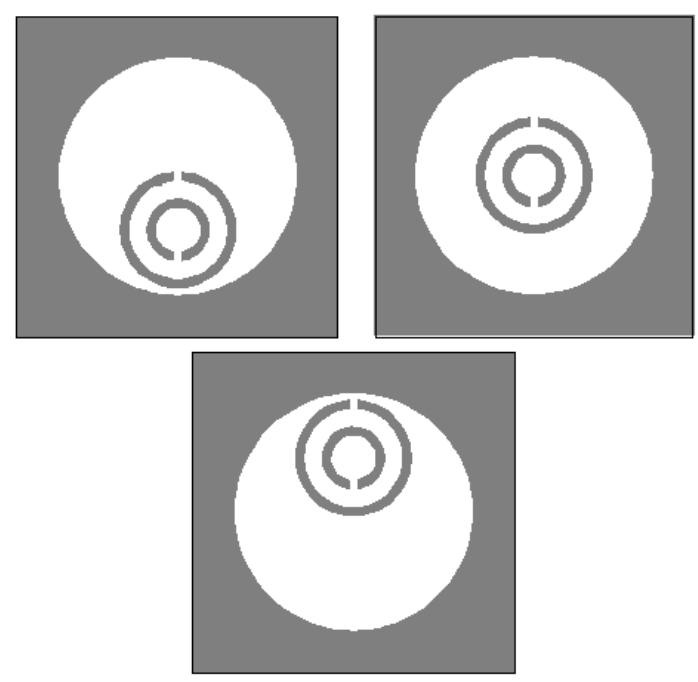

FIG. 3. Geometry of the ground plane of the antenna 1, 2 and 3.

After modeling the standard antenna and the proposed settings, simulations were performed in order to obtain comparative data. A prototype was built for the antenna configuration 1 and standard antenna. The results of the simulations and the measured results of the prototypes constructed are described in the next section.

\section{NUMERICAL INVESTIGATIONS AND EXPERIMENTAL RESULTS}

For the standard antenna and the proposed settings described in the previous section, simulations to obtain values of $S_{11}$ versus frequency were performed. All these values were compared in order to verify the characteristics of all the settings.

Figure 4 shows the simulation of $S_{11}$ as function of the frequency for the standard antenna and proposed settings using the SRR.

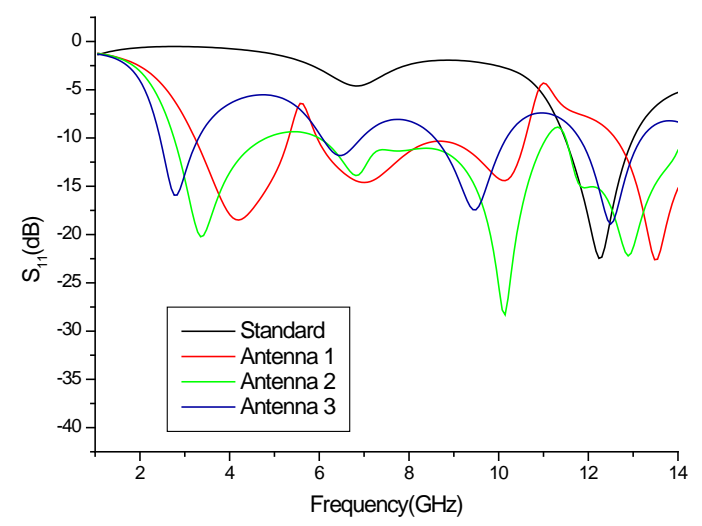

FIG. 4. Values of $\mathrm{S}_{11}$ as function of the frequency to standard antenna and proposed settings. 
It is can see that with the inclusion of this ground plane modified by inserting the SRR, the antenna works well in some frequencies in the range $2-13 \mathrm{GHz}$, which does not occur with the standard antenna. The band of rejection arises due to the resonator and the antenna 1 has better bandwidth with the desired rejection band, while that the antenna 2 does not create the rejection band and the antenna 3 has a lower bandwidth. The bandwidth of this antenna 1 is of 3.2 to $10.6 \mathrm{GHz}$ with a rejection band of 5.3 to $6.0 \mathrm{GHz}$, which makes it a candidate antenna for UWB communication systems.

The gain was also analyzed and Figure 5 shows the radiation patterns in 2D and 3D on the E-plane $\left(\varphi=0^{\circ}\right)$ and Hplane $\left(\varphi=90^{\circ}\right)$, where the antenna proposal has omnidirectional radiation pattern in the H-plane (xz plane) and almost omnidirectional in the E-plane (yz plane), for all configurations.
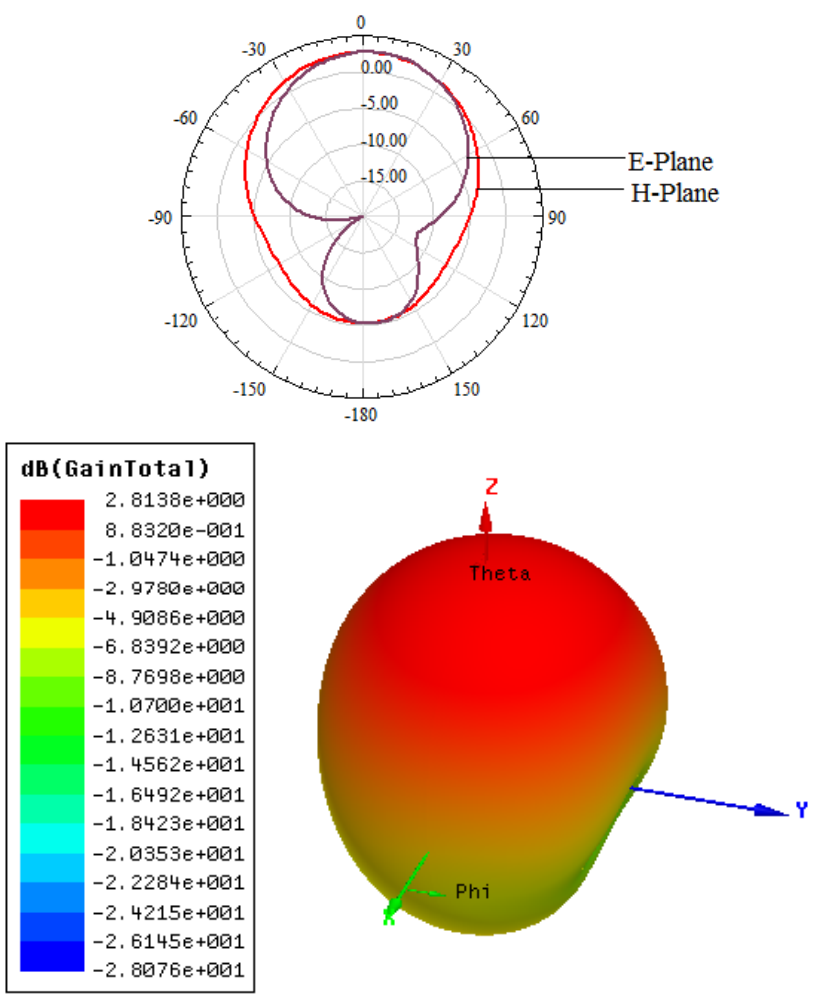

a)
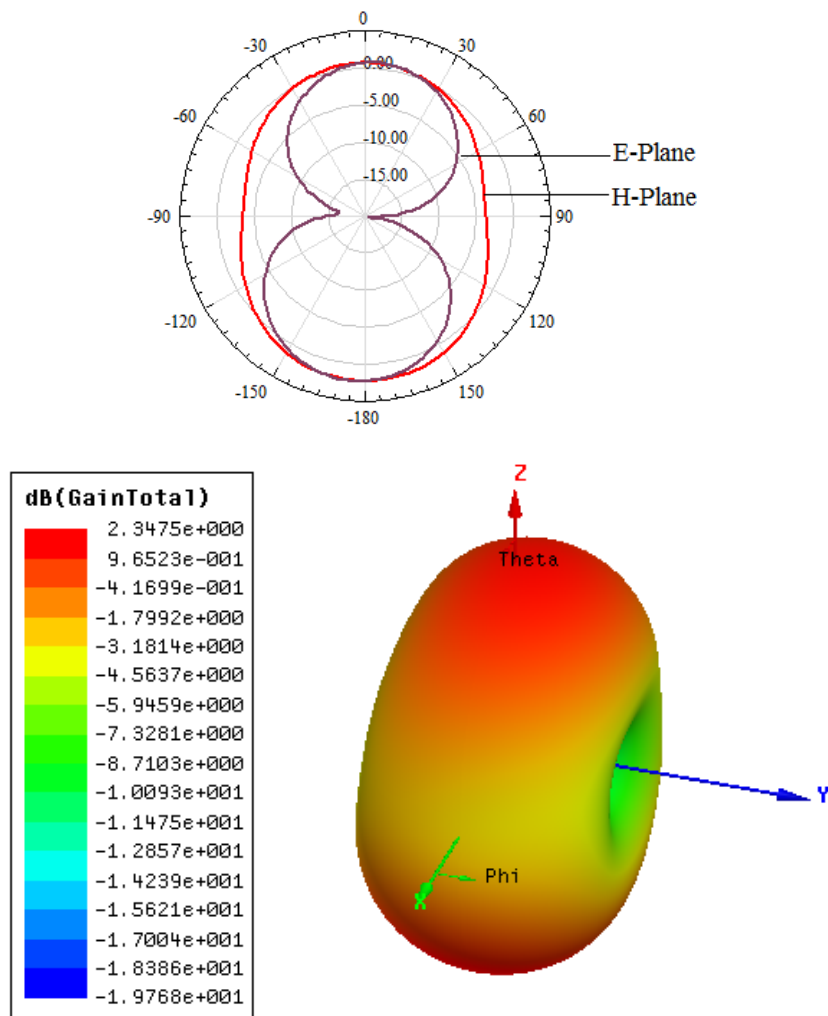

b)
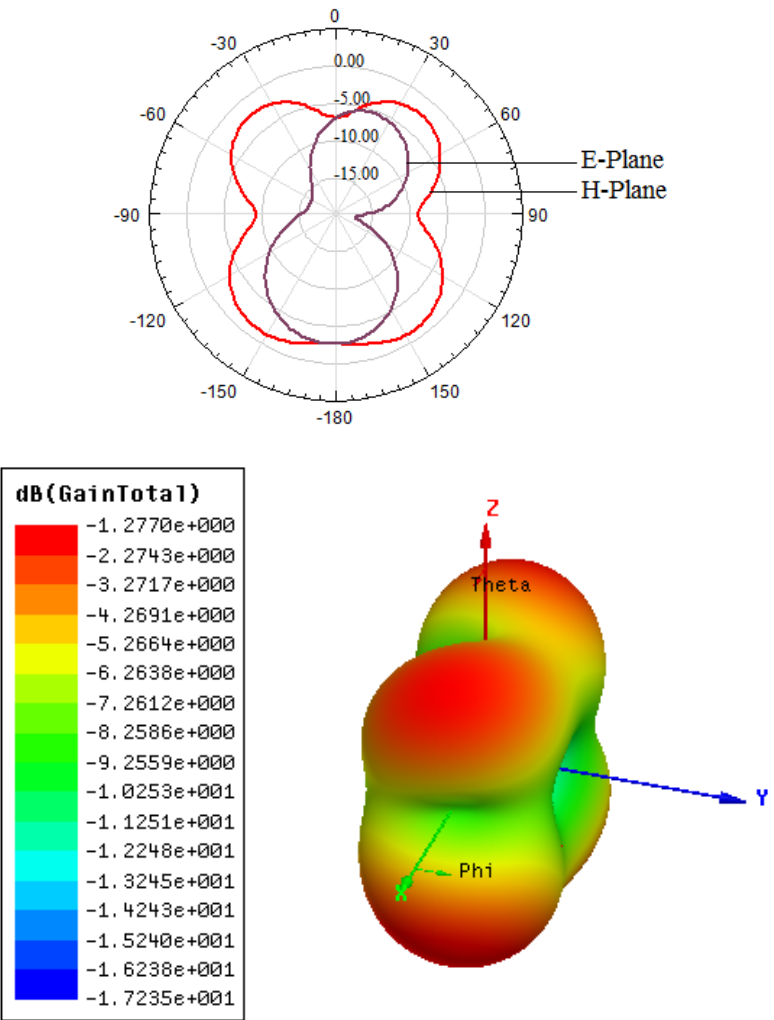

c)

FIG. 5. Simulated results of radiation patterns in 2D and 3D of the E-plane and H-plane to $5.8 \mathrm{GHz}$. a) antenna 1, b) antenna 2, c)antenna 3. 
While the antenna 1 presents gain of $2.814 \mathrm{~dB}$, the antenna 2 presents $2.348 \mathrm{~dB}$ and the antenna 3 presents $-1.277 \mathrm{~dB}$.

The prototypes for the standard antenna and the antenna 1 are constructed as shown in Figures 6 and 7, respectively.
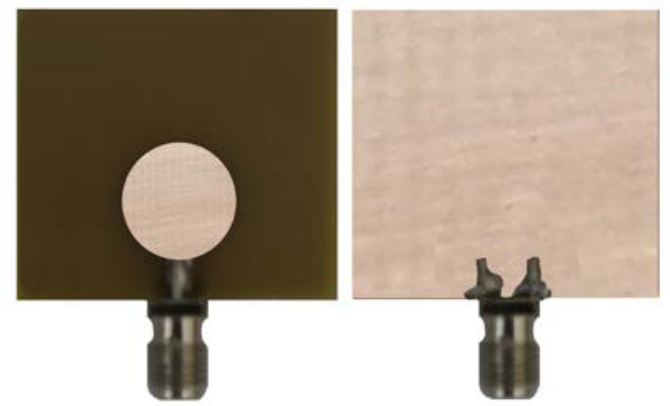

FIG. 6. Standard antenna built.
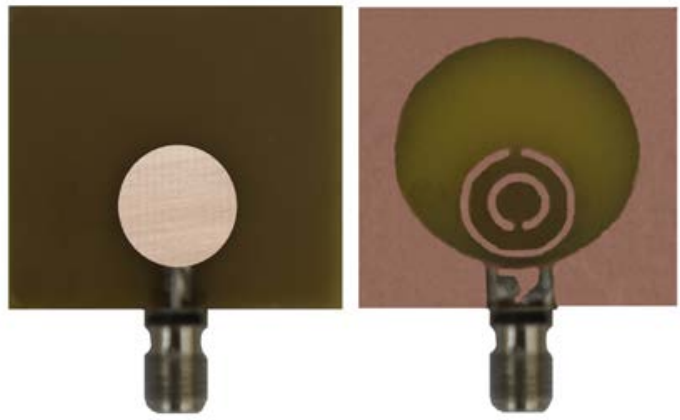

FIG. 7. Antenna 1 built.

Measurements $S_{11}$ as function of the frequency where performed in Rohde \& Schwarz ZVB14, which is a vector Network Analyzer, device that allows the measurement and testing of antennas.

Measurements of $S_{11}$ were performed, and the data from the two antennas, measured and simulated, were compared. This comparison is shown in Figures 8 and 9, respectively.

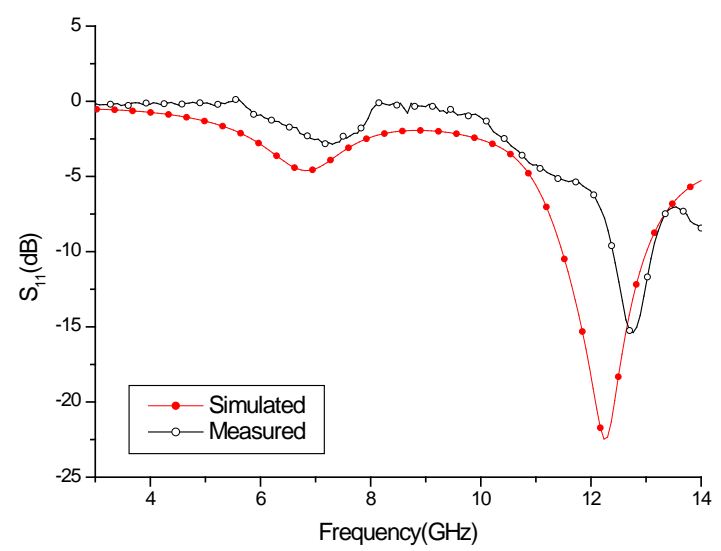

FIG. 8. $\mathrm{S}_{11}$ of the standard antenna.

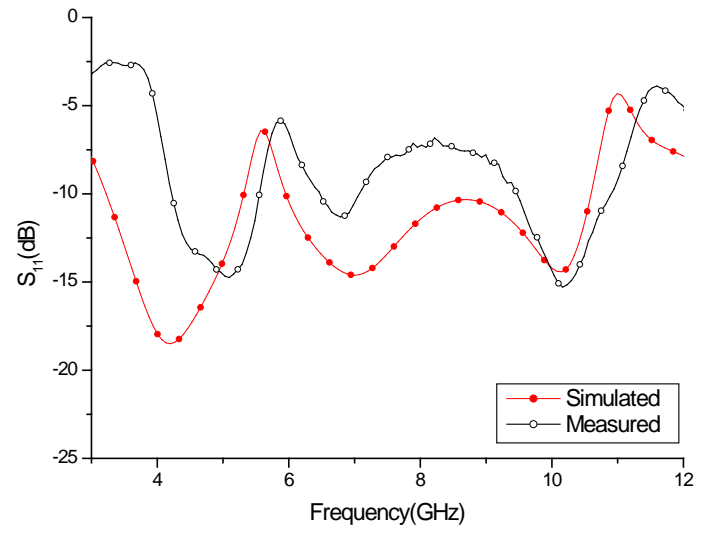

FIG. 9. $\mathrm{S}_{11}$ of the antenna 1.

This comparison shows a good agreement between measured and simulated values. Differences between the two curves are likely to give the misalignment between the two sides during the manufacturing process, and inaccuracies in dimensions.

\section{CONCLUSIONS}

In this paper, a micro strip antenna with Split Ring Resonator - SRR was analyzed using computer simulation. Three configurations are analyzed by varying the position of the SRR. The proposed structure presented an excellent bandwidth of 3.2 to $10.6 \mathrm{GHz}$, when calculated as return loss less than $-10 \mathrm{~dB}$. A rejection band of 5.3 to $6.0 \mathrm{GHz}$ is obtained using SRR that resonates at the required cut-off frequency. Since FR4 is well-known to present high losses at microwave we can observe in radiation patterns that antennas based on metamaterials have a solution interest to these demands, because its peculiar features not usually found in nature, give rise to a whole new range of electromagnetic applications, in order to increase the efficiency of the structures, in a way that was not possible with classical structures. It was observed that the structure of the proposed antenna becomes a candidate for use in wireless communications systems. Prototypes were built and measured data were compared with the simulated.

\section{REFERENCES}

[1] J. Kim, N. Kim, S. Lee, and B. Oh, "Triple band-notched UWB monopole antenna with two resonator structures," Microwave and Optical Technology Letters, Vol. 55, No. 1, 4-6, January 2013. doi: 10.1002/mop.27275

[2] E.B. Marek and M.A. Amin, "Design of UWB planar antenna with improved cut-off at the out-of-band frequencies", IEEE Antennas and Wireless Propagation Letters, Vol. 7, 408-410, 2008. doi: 10.1109/LAWP.2008.2000724

[3] T. A Denidni and M. A. Habib, "Broadband printed CPW-fed circular slot antenna”, Electronics Letters, Vol. 42, No. 3, 135-136, February 2006. doi: $10.1049 / \mathrm{el}: 20063988$ 
[4] S. Barbarino and F. Consoli, "Effect of the substrate permittivity on the features of a planar slot antenna," Microwave and Optical Technology Letters, Vol. 52, No. 4, 935-940, April 2010. doi: 10.1002/mop.25066

[5] J. Yeo,, "Wideband circular slot antenna with tri-band rejection characteristics at 2.45/5.45/8 GHz,” Microwave and Opical Technology Letters, Vol. 50, No. 7, 1910-1914, July 2008. doi: 10.1002/mop.23521

[6] Z., L. Li Yang, and H. Wang, "Investigation on ultra-wideband printed circular monopole antenna with frequency-notched," IEEE International Conference on Microwave and Millimeter Wave Technology, Vol. 4, 1858-1861, April 2008. doi: 10.1109/ICMMT.2008.4540844

[7] S. N., J. Khan and S. He Xiong, "Low profile and small size frequency notched planar monopole antenna from 3.5 to $23.64 \mathrm{GHz}$," Microwave and Optical Technology Letters, Vol. 50, No. 1, 235-236, January 2008. doi: 10.1002/mop.23030

[8] S. Tu, Y.C. Jiao, Y. Song, and Z. Zhang, "A novel miniature strip-line FED antenna with band-notched function for UWB applications," Progress In Electromagnetics Research Letters, Vol. 10, 29-38, 2009. doi:10.2528/PIERL09061105

[9] Z.W. Yu, G.M. Wang, J.G. Liang, and X.J. Gao, "A semicircular bandnotch ultra-wideband printed antenna based on CSRR,” Microwave and Optical Technology Letters, Vol. 52, No. 10, 2387-2390, October 2010. doi: 10.1002/mop.25463

[10] M. P. Sousa Neto, H. C. C. Fernandes and C. G. Moura. "Design of a Ultrawideband Monopole Antenna Using Split Ring Resonator for Notching Frequencies," Mivrowave and Optical Technology Letters, vol. 56, No. 6, 1471- 1473, June 2014. doi: 10.1002/mop.28363

[11] R. Marqués, F. Mesa, J. Martel, and F. Medina, "Comparative analysis of edge- and broadside-coupled split ring resonators for metamaterial design-Theory and experiment," IEEE Transactions on Antennas and Propagation, vol. 51, no. 10, 2572-2581, October 2003. doi:10.1109/TAP.2003.817562

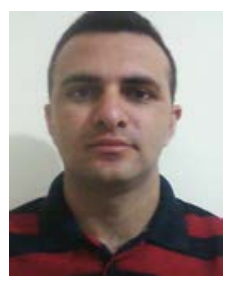

Otávio Paulino Lavor received the degree of Technologist in Human Resource Management from the Methodist University of São Paulo in 2010, BA in Physics from the State University of Ceará in 2011, graduated in mathematics from the Federal University of Ceará in 2011, specializes in Mathematics from the Integrated Faculty of Jacarepaguá in 2012 and the master in Physics from the Federal University of Ceará in 2013. He is currently professor at the Federal Rural University of the Semi-Arid and is studying $\mathrm{PhD}$ in Electrical and Computer Engineering at the Federal University of Rio Grande do Norte, working in telecommunications, mathematics and applied physics.

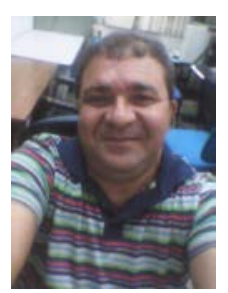

Carlos Gomes de Moura is $\mathrm{PhD}$ in Electrical and Computer Engineering, Federal University of Rio Grande do Norte - UFRN. He has a Master in Electrical and Computer Engineering, specializing in Computer Systems from the UFRN. MBA in corporate finance from FGV, civil engineer from the UFRN and electrical engineer, electronics mode, from the UPE. He works in electrical engineering with emphasis on electromagnetic theory, microwave, wave propagation, antennas and clever arrangements, photonics, metamaterials, wifi and wimax, superconductors, numerical methods.

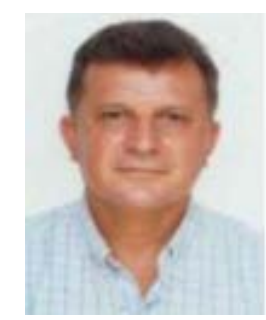

Humberto Cesar Chaves Fernandes was born in Martins-RN, Brazil. He received with laude the BS in Electrical Engineering from the Federal University of Rio Grande do Norte-UFRN, Brazil in 1977, the MSc (1980), PhD (1984) degrees and Postdoctoral program (1986) from the State University of Campinas-UNICAMP, Sao Paulo, Brazil. His current research interests are microwave, millimeter waves, smart antennas array, superconductivity, semiconductor, neural networks, electromagnetic, photonics, metamaterial, dynamic methods and applications. Since 1978, he is at the Electrical Engineering Department from the UFRN, where he is a Senior Researcher and Full Professor. Member of the SBrT (Brazilian Telecommunications Society), IEEE ConSOC (USA), SBMO (Brazilian Microwave and Optoelectronics Society), SBPMat (Brazilian Materials Research Society) and Fellow of the Electromagnetics Academy (USA). He has formed more than 40 master students and $8 \mathrm{PhD}$ students.

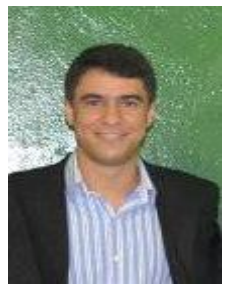

Marinaldo Pinheiro de Sousa Neto completed graduation in 2010, master's degree in 2011 and doctorate in 2014 in Electrical Engineering from the Federal University of Rio Grande do Norte. $\mathrm{He}$ is currently a Professor at the Federal Institute of Education, Science and Technology of Rio Grande do Norte, acting on the following topics: Metamaterial, TTL method and planar 